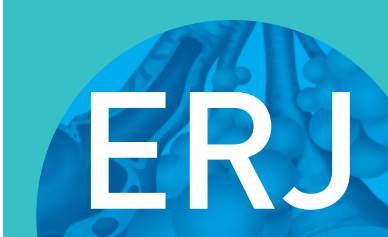

open research

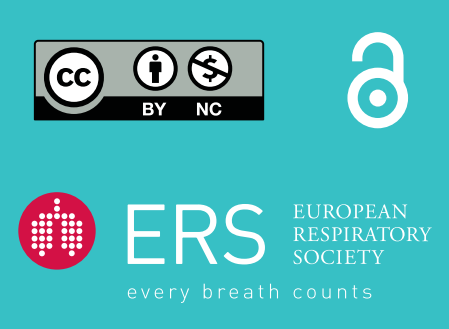

\section{Development and validation of an open-source, disposable, 3D-printed in vitro environmental exposure system for Transwell culture inserts}

\author{
Abiram Chandiramohan ${ }^{1,5}$, Mohammedhossein Dabaghi ${ }^{1,5}$, Jennifer A. Aguiar², \\ Nicholas Tiessen ${ }^{1}$, Mary Stewart ${ }^{1}$, Quynh T. Cao ${ }^{1}$, Jenny P. Nguyen ${ }^{1}$, \\ Nima Makhdami ${ }^{1}$, Gerard Cox ${ }^{1}$, Andrew C. Doxey ${ }^{1,2}$ and Jeremy A. Hirota ${ }^{1,2,3,4}$
}

Affiliations: ${ }^{1}$ Firestone Institute for Respiratory Health - Division of Respirology, Dept of Medicine, McMaster University, Hamilton, ON, Canada. ${ }^{2}$ Dept of Biology, University of Waterloo, Waterloo, ON, Canada. ${ }^{3}$ McMaster Immunology Research Centre, McMaster University, Hamilton, ON, Canada. ${ }^{4}$ Division of Respiratory Medicine, Dept of Medicine, University of British Columbia, Vancouver, BC, Canada. ${ }^{5}$ These authors contributed equally.

Correspondence: Jeremy A. Hirota, Firestone Institute for Respiratory Health - Division of Respirology, Department of Medicine, McMaster University, Hamilton, ON, L8N 4A6, Canada. E-mail: hirotajaAmcmaster.ca

ABSTRACT Accessible in vitro models recapitulating the human airway that are amenable to study whole cannabis smoke exposure are needed for immunological and toxicological studies that inform public health policy and recreational cannabis use. In the present study, we developed and validated a novel three-dimensional (3D)-printed in vitro exposure system (IVES) that can be directly applied to study the effect of cannabis smoke exposure on primary human bronchial epithelial cells.

Using commercially available design software and a 3D printer, we designed a four-chamber Transwell insert holder for exposures to whole smoke. COMSOL Multiphysics software was used to model gas distribution, concentration gradients, velocity profile and shear stress within IVES. Following simulations, primary human bronchial epithelial cells cultured at the air-liquid interface on Transwell inserts were exposed to whole cannabis smoke using a modified version of the Foltin puff procedure. Following $24 \mathrm{~h}$, outcome measurements included cell morphology, epithelial barrier function, lactate dehydrogenase (LDH) levels, cytokine expression and gene expression.

Whole smoke delivered through IVES possesses velocity profiles consistent with uniform gas distribution across the four chambers and complete mixing. Airflow velocity ranged between 1.0 and $1.5 \mu \mathrm{m} \cdot \mathrm{s}^{-1}$ and generated low shear stresses $(<<1 \mathrm{~Pa})$. Human airway epithelial cells exposed to cannabis smoke using IVES showed changes in cell morphology and disruption of barrier function without significant cytotoxicity. Cannabis smoke elevated interleukin-1 family cytokines and elevated CYP1A1 and CYP1B1 expression relative to control, validating IVES smoke exposure impacts in human airway epithelial cells at a molecular level.

The growing legalisation of cannabis on a global scale must be paired with research related to potential health impacts of lung exposures. IVES represents an accessible, open-source, exposure system that can be used to model varying types of cannabis smoke exposures with human airway epithelial cells grown under air-liquid interface culture conditions.

@ERSpublications

Development of an open-source, disposable, 3D-printed in vitro environmental exposure system for Transwell culture inserts that can be used for environmental exposures important for lung health, and validation with cannabis smoke exposure https://bit.ly/2JjgDrm

Cite this article as: Chandiramohan A, Dabaghi M, Aguiar JA, et al. Development and validation of an open-source, disposable, 3D-printed in vitro environmental exposure system for Transwell culture inserts. ERJ Open Res 2021; 7: 00705-2020 [https://doi.org/10.1183/23120541.00705-2020].

This article has supplementary material available from openres.ersjournals.com

Data availability: All data will be provided upon request.

Received: 28 Sept 2020 | Accepted: 23 Nov 2020

Copyright $\odot$ ERS 2021. This article is open access and distributed under the terms of the Creative Commons Attribution Non-Commercial Licence 4.0. 


\section{Introduction}

The lung is responsible for gas exchange between the outside world and the human body. During ventilation, the lungs are in contact with the external environment and exposed to air that may contain a variety of pathogens, including allergens, viruses, bacteria, and air pollutants, including organic combustion by-products [1]. The pseudo-stratified airway epithelial cells that line the lungs have evolved to mitigate the risks from external insults, providing a tight physical and immunological barrier [2-4]. It contributes to coordinated immune responses, including mucus production and airway surface-lining fluid secretion, cytokine and chemokine secretion for local and systemic immune cell recruitment, and antimicrobial protein secretion in response to environmental assaults $[5,6]$. Airway epithelium dysfunction has been strongly implicated in the pathogenesis of many airway diseases including asthma, COPD, and pulmonary fibrosis [7-9]. Importantly, environmental insults capable of damaging the airway epithelium are also risk factors for these same respiratory diseases [10-13].

Tobacco smoking, a direct environmental insult to the airway epithelium, remains common on a global scale, despite well-described effects on respiratory health [14-18]. Similar to tobacco smoke, cannabis smoking is also a direct environmental attack to the lungs. As a result of progressive legalisation on a global scale, cannabis consumption has been on the rise, where $90 \%$ of consumers prefer smoking as a route of delivery $[19,20]$. Tobacco and cannabis smoke exposure induce similar clinical features such that both environmental exposures are associated with increased prevalence of coughing, wheezing, chest tightness, and risk for developing COPD [21-23]. Tobacco and cannabis smoke exposure also present divergent clinical features, with tobacco smokers more likely to develop lung cancer relative to cannabis smokers $[24,25]$. This observed divergence may be due to the presence of phytocannabinoids with anti-inflammatory properties unique to cannabis [26-29]. The uncertainty surrounding the health effects of cannabis smoke and discrepancies with the known negative impacts of tobacco smoke warrants further investigation to inform government policies, recreational practices and cultivation strategies in an era of broadening acceptance for legal and open markets.

In vitro smoke exposure models using human airway epithelial cells have been crucial for tobacco smoke research and will likely be important for cannabis smoke research [30, 31]. A proportion of available smoke exposure research, primarily with tobacco, has been established through submerged monolayer culture designs in which smoke extract has been used to expose cells [32-34]. Our group has recently applied these methods to Calu-3 cells with cannabis smoke extract exposure and observed an induction of a proinflammatory cytokine response and suppression of antiviral cytokines [35, 36]. Smoke extract exposures do not entirely reflect whole smoke exposure as the latter generates heat and water-insoluble hydrocarbon combustion products [21,37-39]. Additionally, submerged monolayer cell culture designs do not entirely reflect the in situ airway environment where a pseudo-stratified airway epithelium is exposed to inhaled air on an apical side while attached to a basement membrane on the basal side. To more accurately model the in situ environment, airway epithelial cells can be cultured on Transwell inserts under air-liquid interface (ALI) culture conditions to create a pseudo-stratified tissue structure [40, 41]. Transwell inserts of airway epithelial cells under ALI can be used for whole smoke exposures using advanced systems that model inhalation and exhalation patterns of humans [40,41]. The strengths and limitations of popular smoke-generating machines have been characterised extensively [42-45]. Commercially available smoking machines offer high throughput designs and are able to accommodate multiple cigarettes or cell culture plates that can be exposed with independent syringes, allowing for control over the parameters of each exposure under automated conditions [45]. Some devices are directly amenable to multiple exposures beyond smoke, including environmental toxins, gases, therapeutic aerosols, aerosolised pathogens, and other volatile compounds [42-45]. The throughput and automation benefits of these environmental exposure systems are offset by some important limitations [45-49]. From an operations perspective, these are capital intensive closed systems that cannot be customised, limiting accessibility to specialised research facilities and field participants [45]. From a technical perspective, limitations may include potential air and smoke mixing inefficiencies, ageing of smoke in mixing vessels, and turbulence that is inconsistent with lung physiology [45]. Collectively, the development and validation of a low-cost in vitro environmental exposure system for Transwell culture inserts of ALI cultured airway epithelial cells will broaden the ability of researchers to perform essential research related to cannabis smoke exposure and lung health.

To address existing constraints with environmental exposure systems and related research, we propose that additive manufacturing, such as three-dimensional (3D) printing, can function as a disruptive solution to create an open-source, disposable, in vitro exposure system that is widely accessible without requiring specialised environmental exposure infrastructure. Additive manufacturing has been utilised in various fields to realise complex $3 \mathrm{D}$ constructs with resolution at the micron level. In contrast to conventional manufacturing technologies, additive manufacturing is accessible and independent of specialised 
technologies or personnel, with widely available commercial 3D printers able to rapidly generate functional designs based on computer aided design (CAD) files. Additive manufacturing technologies have accelerated prototyping steps while reducing costs, effectively enabling researchers with limited design training to optimise novel designs independent of historical manufacturing constraints. Importantly, commercially available and capital accessible additive manufacturing technologies are sufficient for the medium throughput production that is required at a standard research laboratory scale.

In the present study, we develop and validate an open-source, disposable, 3D-printed in vitro environmental exposure system for Transwell culture inserts and apply to study the effect of whole cannabis smoke on primary human bronchial epithelial cells (HBECs). Our in vitro exposure system (IVES) is widely accessible due to the open-source CAD file, amenability to commercially available 3D printers, and design for widely used Transwell culture inserts. We validate our model with cannabis smoke laying a foundation for additional modalities, including tobacco smoke and vaping products. IVES also gives the capacity for four Transwell inserts to be exposed to the same environmental exposure, providing medium throughput, while reducing variability that may occur with independent exposures for separate Transwells. Finally, IVES is amenable to dilution of smoke with room air for adaptation to concentration-response studies. Using cannabis smoke as an exposure of current public health importance, we validate IVES with primary HBECs and demonstrate an impact of the exposure on epithelial barrier function, interleukin (IL)-1 family cytokine expression and expression of genes involved in cellular detoxification.

\section{Materials and methods \\ System design}

Autodesk Inventor 2018 software was used for all designs. The IVES units were 3D printed with a FormLabs Form 2 printer using clear resin (RS-F2-GPCL-04, MA, USA). IVES contains four Transwell exposure chambers, two inlets, four outlets, and four chamber caps (figure 1). Each inlet is distributed to each of the four exposure chambers. Inlet diameter was optimised at $3 \mathrm{~mm}$ to minimise obstruction with organic combustion by-products. Exposure chamber size was designed based on the dimension of a Transwell insert for 24 well-plate (VWR, catalogue number: 29442-082). In addition, the location of the inlet and outlet of each chamber was designed such that Transwell inserts would experience indirect exposures of turbulent air. Each chamber had an outlet for exhaust from the chamber. Threaded caps for the exposure chambers created seals that eliminated exhaust through this path. IVES has been validated using Corning Transwell inserts. Distinct Transwell inserts of similar dimensions will be adaptable to the

FIGURE 1 Three-dimensional schematic view of the in vitro exposure system. As shown, air or exposure (e.g. smoke) delivered to the inlet is equally distributed across the four exposure chambers which house the Transwell inserts. Circulated air or exposure le.g. smokel exits passively through the outlet in each exposure chamber. Scale bar $=1 \mathrm{~cm}$.

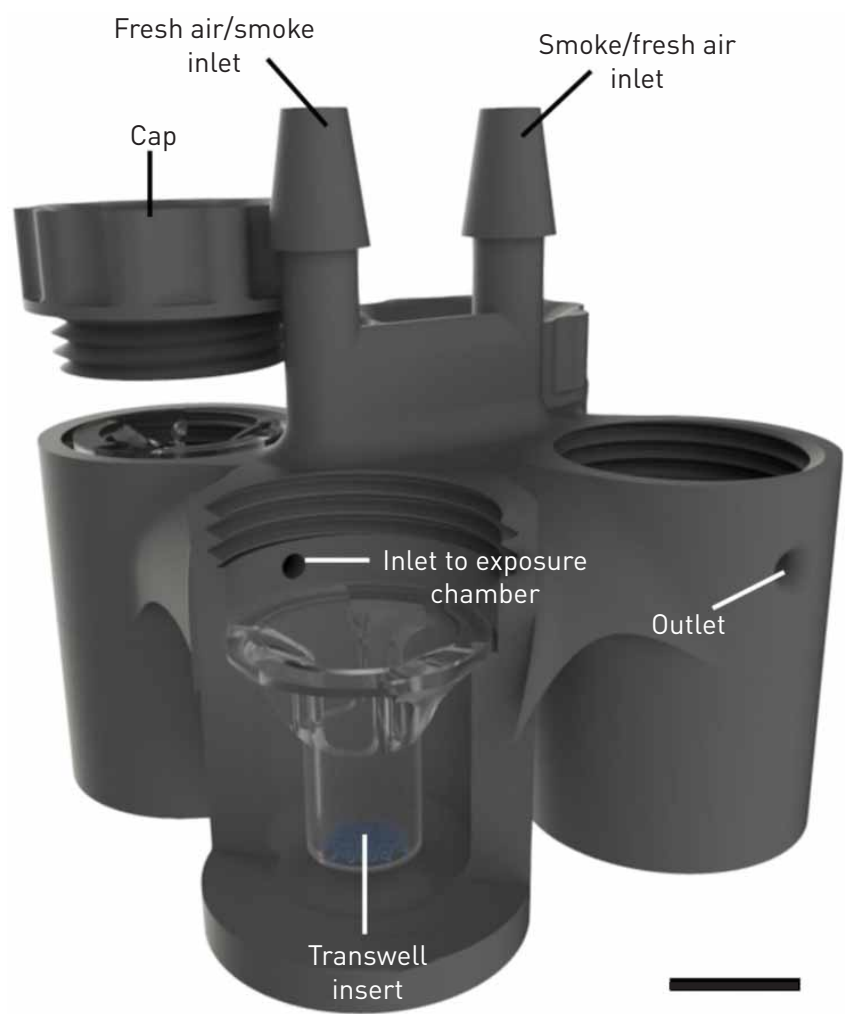


IVES design, whereas Transwells from different manufacturers with different dimensions may need independent validation. The IVES design file is deposited in the online supplement as a stl file format.

\section{Fluid dynamic modelling}

During design phases, a quantitative simulation of fluid dynamics was performed using COMSOL Multiphysics software to model the gas distribution and concentration gradients in the IVES unit. To model the velocity profile and shear stress, the entire fluidic path from the merged inlet to the chambers and the outlets was included. The main purpose of this simulation was to ensure that the gas was equally distributed among all chambers with minimal shear stress experienced at the surface of Transwell inserts. Air was used as the gas of interest in this part of the simulation, under the assumption that air was behaving as a Newtonian fluid. The governing equations used in the simulation as follows:

$$
\begin{gathered}
\rho \nabla \cdot(\vec{\vartheta} \vec{\vartheta})=-\nabla p+\nabla \cdot \underline{\tau}+\rho \vec{g}+S_{r} \\
\nabla \cdot(\rho \vec{\vartheta})=0
\end{gathered}
$$

where $\rho$ is the air density, $\vec{\vartheta}$ represents the velocity vector field, p shows the pressure, $\underline{\tau}$ expresses the stress tensor field, $\vec{g}$ is the gravitational force, and $S_{r}$ shows any possible external source term. The acceleration forces, including both the local and the conventional forces, are expressed on the left side of equation 1, and the forces created by pressure gradient and viscosity are described on the right side of the equation. A no-slip condition on the walls was assumed for the entire IVES unit, with the model assuming no back-flow. A gas flow rate of $7 \mathrm{~mL} \cdot \mathrm{s}^{-1}$ was used as the boundary condition and the gas flow direction was set to be normal to the inlet and outlets. Equation 2 expresses the mass conservation for the exposure unit. In the simulation, initial values were set to zero. Then, the simulation was studied under a steady-state condition.

\section{Cell culture}

All studies using human cells were approved by the Hamilton Integrated Research Ethics Board (approval: 5305T). Primary HBECs were isolated from a bronchial brushing from consented subjects undergoing routine clinical procedures, and plated into T25 flasks containing PneumaCult Ex-Plus Basal medium (StemCell Technologies; catalogue number 05040) with PneumaCult Ex-Plus 50× supplement, 0.01\% hydrocortisone stock solution (StemCell Technologies; catalogue number 7925) and $1 \%$ antibiotic-antimycotic (Thermo Fisher Scientific; catalogue number 15240062). Once cultures achieved $\sim 80 \%$ confluence, cells were passaged at a density of 50000-100000 cells per insert into polyester Transwell inserts for exposure experiments. Cells were fed with $200 \mu \mathrm{L}$ and $750 \mu \mathrm{L}$ of PneumaCult Ex-Plus Basal medium in the apical and basal compartments respectively. Once cultures reached $100 \%$ confluency, apical medium was removed, and culture inserts were fed from the basal side to bring cultures to ALI (day 0 of ALI). Following $24 \mathrm{~h}$, culture inserts were fed from the basal compartment with $750 \mu \mathrm{L}$ of PneumaCult-ALI Basal medium (StemCell Technologies; catalogue number 05001) with PneumaCult-ALI 10× supplement, PneumaCult-ALI Maintenance $100 \times$ Supplement, $1 \%$ antibiotic-antimycotic, $0.5 \%$ hydrocortisone stock solution and $0.2 \%$ heparin solution (StemCell Technologies; catalogue number 7980) to support development and differentiation of a pseudo-stratified epithelial culture (day 1 of ALI). Transwell cultures were fed from the basal compartment and a PBS wash was performed on the apical compartment every other day. Exposure experiments were performed between day 14 and day 15 of ALI culture.

\section{Cannabis material and cigarette manufacturing}

A Kentucky research-grade cigarette (Lot:3R4f) contains $\sim 0.7 \mathrm{~g}$ of dried tobacco leaves and has been used extensively for in vitro studies. Using research-grade tobacco cigarettes as a reference, cannabis cigarettes with $\sim 0.7 \mathrm{~g}$ of dried cannabis flower ( $\sim 10 \%$ THC, 0\% CBD; Purple Sun God, lot: 00117 (b161)) were manufactured with RAW rolling papers and cardboard filters. Cannabis was purchased from the Ontario Cannabis Store with a Health Canada-approved research license.

\section{Epithelial barrier function assessment}

Transepithelial electrical resistance (TEER) was measured using a Millicell ERS-2 Voltohmmeter (EMD Millipore, Etobicoke, Ontario, Canada) to quantify epithelial barrier function according to manufacturer's directions. TEER was measured before and $24 \mathrm{~h}$ after exposures (air or smoke).

\section{Exposure protocol}

In a biosafety cabinet, $800 \mu \mathrm{L}$ of PneumaCult-ALI medium was added into each individual chamber of the IVES unit. Transwell inserts were transferred into the IVES and left in a $37^{\circ} \mathrm{C}, 5 \% \mathrm{CO}_{2}$ humidified 
incubator to equilibrate for $10 \mathrm{~min}$ before exposures. In a fume hood, exposures were performed with a 50-mL syringe connected to the fresh air inlet of the IVES through a PVC Tygon tube (length: $32 \mathrm{~cm}$, lumen diameter: $2 \mathrm{~mm}$ ) and a three-way valve (figure 2). Another $50-\mathrm{mL}$ syringe was connected to the smoke exposure inlet on the IVES through a PVC Tygon tube (length: $32 \mathrm{~cm}$, lumen diameter: $2 \mathrm{~mm}$ ) and a three-way valve. For the experiments with cannabis, a cigarette was placed into another PVC Tygon tube (length: $32 \mathrm{~cm}$, lumen diameter: $8 \mathrm{~mm}$ ), with the opening sealed with parafilm and connected to the three-way valve. The dose was administered according to a modified version of the Foltin puff procedure [50-55]. This procedure, optimised for our model, consisted of one puff of smoke separated by three puffs of fresh room air to mimic the behaviour of human smoking patterns. Each puff of smoke or room air was $35 \mathrm{~mL}$ in volume and was perfused over the Transwell insert at a rate of $7 \mathrm{~mL} \cdot \mathrm{s}^{-1}$. Between each puff, the cells were undisturbed for $10 \mathrm{~s}$. Each experimental group received one cigarette smoked to completion using this regimen. Cells were exposed to freshly generated smoke outside of an incubator in a fume hood on a $37^{\circ} \mathrm{C}$ heating bed until the $0.7 \mathrm{~g}$ hand-rolled cannabis cigarette was entirely combusted ( $\left.20 \mathrm{~min}\right)$. Control conditions received as many puffs of room air as the corresponding experimental condition received smoke under the same regimen. Following exposure, inserts were immediately transferred to a new plate with $600 \mu \mathrm{L}$ of PneumaCult-ALI medium in the basal compartment. Plates were then transferred to a $37^{\circ} \mathrm{C}, 5 \% \mathrm{CO}_{2}$ humidified incubator. Twenty-four hours later, basal and apical medium was collected, spun down at $7500 \times \mathrm{g}$ and $4^{\circ} \mathrm{C}$ for $15 \mathrm{~min}$ and supernatants were stored at $-80^{\circ} \mathrm{C}$ for subsequent quantification of cytokines and assessment of cytotoxicity.

\section{Quantification of cytokines}

Cell culture medium was collected and spun down at $7500 \times \mathrm{g}$ for $15 \mathrm{~min}$ at $4^{\circ} \mathrm{C}$. Apical supernatants were subsequently analysed via a 42-plex multiple cytokine array (Eve Technologies, Calgary, Alberta, Canada).

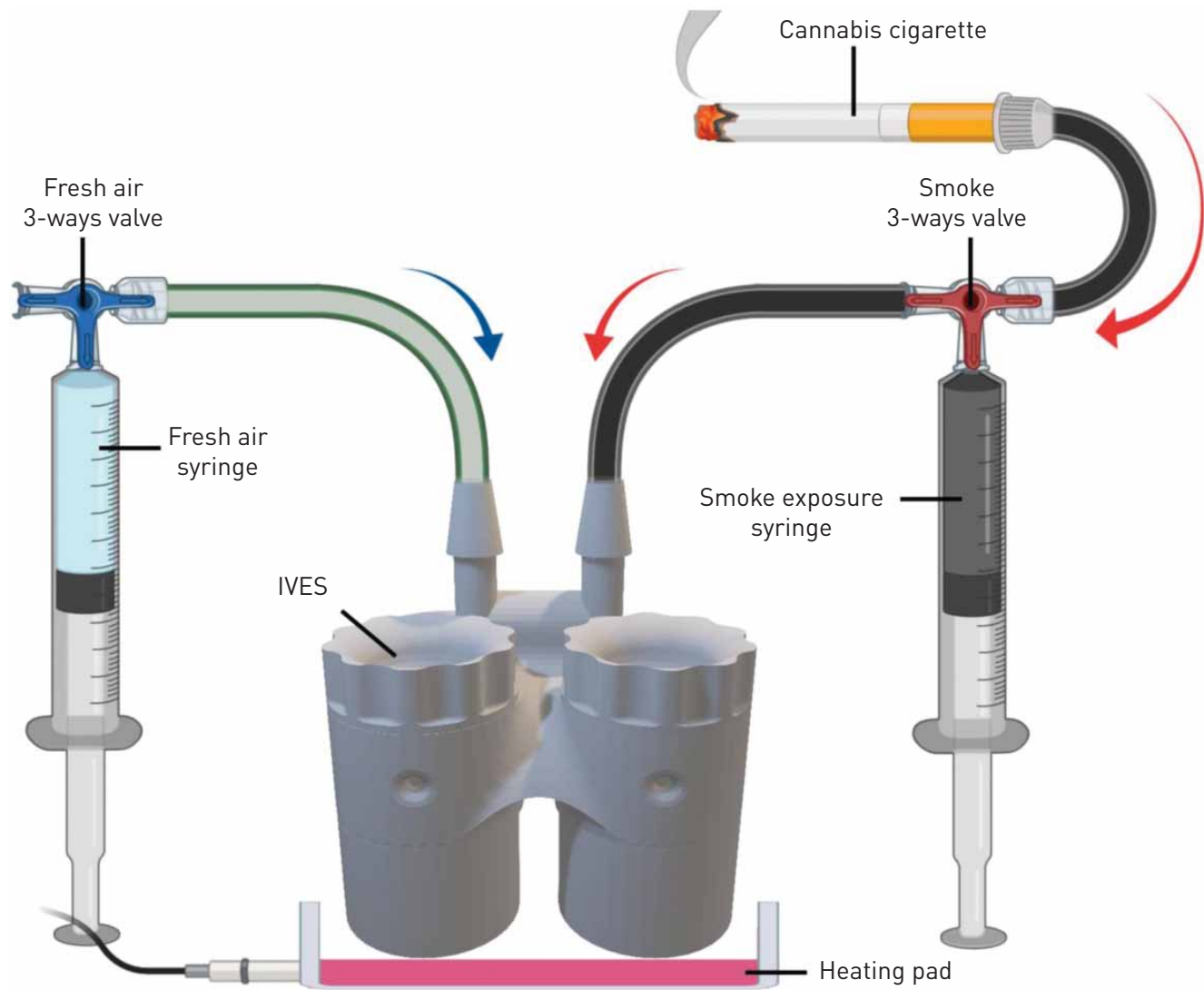

FIGURE 2 A schematic depicting the in vitro exposure system (IVES) connected to air and smoke sources. A three-way valve connects the cannabis cigarette to IVES through a $50-\mathrm{mL}$ syringe. Another three-way valve connects room air to IVES. Smoke is drawn through the smoke exposure syringe and expelled with predetermined rate and volume into IVES. Room air is introduced with the fresh air syringe in a similar fashion. A heating pad positioned below IVES maintains the experimental system at $37^{\circ} \mathrm{C}$ (figure generated with BioRender). 
Cell membrane integrity and cytotoxicity

A CYTOQUANT lactate dehydrogenase (LDH) Cytotoxicity Assay kit (Thermo Fisher Scientific; catalogue number C20301) was used according to the manufacturer's guidelines with positive controls used to indicate maximal LDH release.

RNA isolation, purification and transcriptomic analysis

Following collection of apical and basal media $24 \mathrm{~h}$ after exposure, total RNA was extracted and isolated using an RNeasy Kit (QIAGEN, Toronto, Ontario, Canada). Cells in each Transwell were lysed in $100 \mu \mathrm{L}$ of RLT Isolation Buffer with $1 \% \beta$-mercaptoethanol $(2 \mathrm{Me})(\mathrm{v} / \mathrm{v})$ and stored at $-80^{\circ} \mathrm{C}$. Subsequently, RNA was purified using the manufacturer's protocol and quantified via Nanodrop200. cDNA was prepared and underwent transcriptomic analysis using Clariom S Microarray chips (Thermo Fisher Scientific, Mississauga, Ontario, Canada).

Processing of raw microarray data

Raw intensity values from the Clarion $\mathrm{S}$ microarray experiment were imported into the $\mathrm{R}$ statistical language environment (version 3.6.1; R Core Team, 2019). Probe definition files were obtained from the Brainarray database (version 24) [56]. The single channel array normalization (SCAN) method was used to obtain $\log _{2}$-transformed normalised expression values with the SCAN.UPC R package (version 2.26.0) [57], with annotation data from the Bioconductor project (version 3.9) [58].

\section{Statistical analysis}

All statistical tests were performed on GraphPad Prism 8 version 8.3.0 (GraphPad Headquarters, San Diego, CA, USA). A paired t-test was performed to assess significance between the differences in epithelial barrier function between the control group and experimental group. An ANOVA followed by a Tukey's post hoc test was performed to assess differences in cell cytotoxicity following smoke exposure. Differences in cytokine expression were assessed using paired t-tests. A p-value $<0.05$ was considered statistically significant.

\section{Results}

\section{IVES fluid dynamic modelling}

A mesh analysis was conducted to determine the finest mesh resolution. The mesh size varied from coarse to extra fine, and the mesh size was chosen to be finer as no significant change was recognised by changing the mesh size from finer to extra fine. A defined mesh resolution was chosen to run all simulations for fluid dynamic modelling (figure 3) with a 3D view of velocity streamlines presented (figure $3 \mathrm{a}-\mathrm{d})$. The purpose of the streamlines is to show vortices in IVES after air exposure with a flow rate of $7 \mathrm{~mL} \cdot \mathrm{s}^{-1}$. Quantitative values for the velocity profile were consistent with a uniform gas distribution with complete mixing (streamlines) (figure $3 \mathrm{e}$ ). In addition, the velocity profile (figure $3 \mathrm{f}$ ) and the shear stress profile (figure $3 \mathrm{~g}$ ) at the Transwell insert growth area location was simulated, investigating the impact of the exposure to the cells growing on this surface. Airflow velocity at an approximation of cell location was $1.0-1.5 \mu \mathrm{m} \cdot \mathrm{s}^{-1}$ and generated shear stresses $(<<1 \mathrm{~Pa})$.

Internal gas diffusion inside a chamber was quantified with $\mathrm{CO}_{2}$, a product of combustion, as the gas of interest with an assumption of $1 \mathrm{~mol} \cdot \mathrm{L}^{-1}$ at the inlet with normal diffusion in the air $\left(\mathrm{CO}_{2}\right.$ as the gas of the interest was assumed to be transported in air by diffusion and convection). For this part of the simulation, mass transport of $\mathrm{CO}_{2}$ was coupled with the laminar flow study, which was used to model the velocity profile in IVES. As the gas was uniformly distributed among all four exposed chambers (figure 3), only one chamber was considered in the modelling (the gas flow at the inlet was assumed to be $\left.1.75 \mathrm{~mL} \cdot \mathrm{s}^{-1}\right)$. The simulation was studied dependent on time, and the $\mathrm{CO}_{2}$ diffusion was modelled over $5 \mathrm{~s}$, which was the time of exposure. It was assumed that the $\mathrm{CO}_{2}$ concentration at the outlet was zero (the boundary condition for $\mathrm{CO}_{2}$ concentration at the outlet was assumed to be zero). A full cycle of smoke-fresh air was studied, and the cycle included one smoke exposure for $5 \mathrm{~s}$ (the initial concentration was set to zero; it was assumed that there was no $\mathrm{CO}_{2}$ in the chamber at the beginning) and one continuous fresh air exposure for $15 \mathrm{~s}$ (the initial concentration was taken from the final average volumetric concentration of the smoke exposure after $5 \mathrm{~s}$ resting based on the experimental set-up). To model the mass transport of $\mathrm{CO}_{2}$ in the chamber, Fick's law was used as described below:

$$
\frac{\partial C_{\mathrm{CO}_{2}}}{\partial t}=D_{\mathrm{CO}_{2}}\left(\frac{\partial^{2} C_{\mathrm{CO}_{2}}}{\partial x^{2}}+\frac{\partial^{2} C_{\mathrm{CO}_{2}}}{\partial y^{2}}+\frac{\partial^{2} C_{\mathrm{CO}_{2}}}{\partial z^{2}}\right)
$$

where $C_{\mathrm{CO}_{2}}$ is the $\mathrm{CO}_{2}$ concentration in the smoke exposure chamber and $D_{\mathrm{CO}_{2}}\left(D_{\mathrm{CO}_{2}}=0.16 \mathrm{~cm}^{2} \cdot \mathrm{s}^{-1}\right)$ [59] is the diffusion coefficient of $\mathrm{CO}_{2}$ molecules in the chamber. 

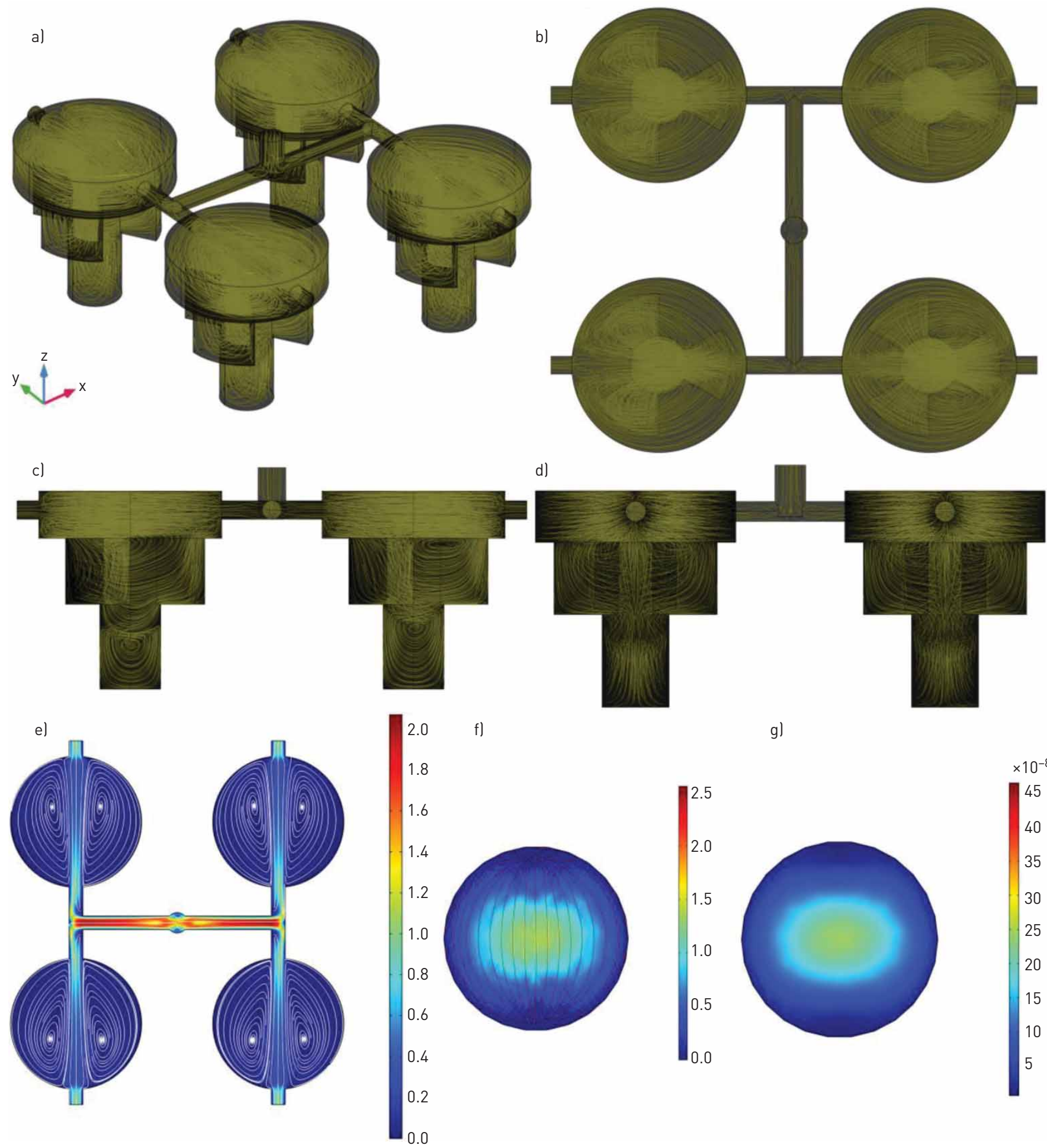

g)

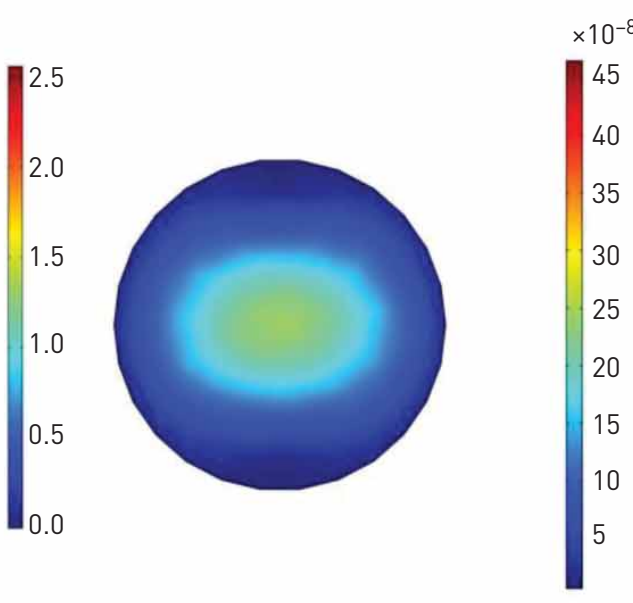

FIGURE 3 Quantitative simulation for in vitro exposure system (IVES) using COMSOL Multiphysics with air used as the gas of interest for simulation. a) A three-dimensional view of the IVES with air flow streamlines showing vortices in IVES and how gases distribute. b) Top view with gas flow streamlines. $c$ and d) The side views with gas flow streamlines. e) The top view of the velocity profile $\left(\mathrm{m} \cdot \mathrm{s}^{-1}\right)$ for the modelled gas presenting a uniform flow distribution among all four exposure chambers with a gentle velocity decrease. $\mathrm{f}$ ) The velocity profile $\left(\mu \mathrm{m} \cdot \mathrm{s}^{-1}\right)$ at the close approximation to the surface where the cells were cultured. g) The shear stress (Pa) profile at the location that the cells were cultured. It should be noted that both air and smoke inlets are merged into a larger duct which is only shown in this figure.

The concentration distribution of $\mathrm{CO}_{2}$ in the chamber over $5 \mathrm{~s}$ of exposure is presented in figure $4 \mathrm{a}$ with streamlines representing the concentration gradient in the chamber. After each smoke exposure, there was a 10 -second resting time to allow the $\mathrm{CO}_{2}$ concentration to become uniform in the entire chamber. 


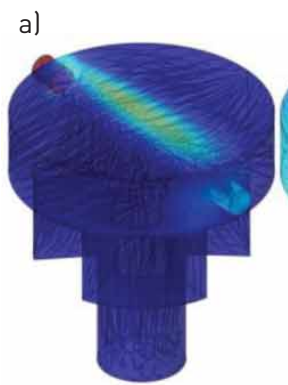

$t=0.1 \mathrm{~s}$

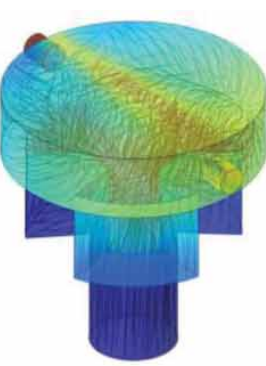

$t=1 \mathrm{~s}$

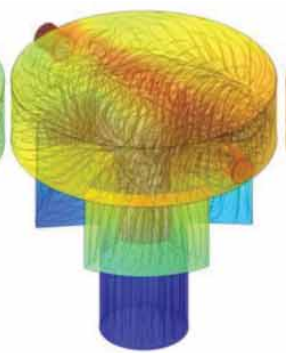

$t=2 \mathrm{~s}$

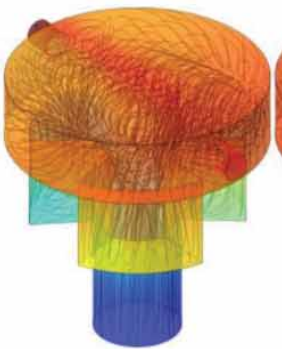

$t=3 \mathrm{~s}$

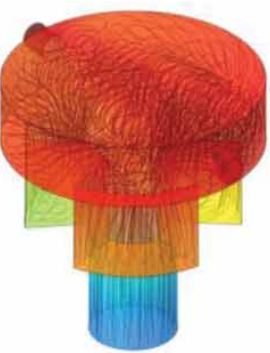

$t=4 \mathrm{~s}$

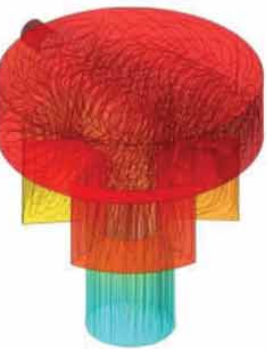

$t=5 \mathrm{~s}$

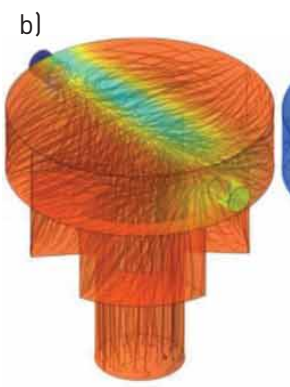

$t=5.1 \mathrm{~s}$

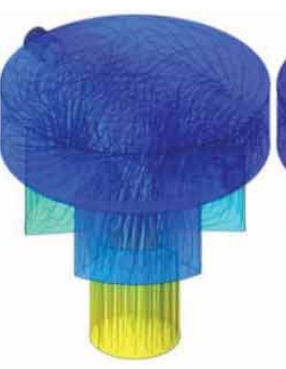

$t=8 \mathrm{~s}$

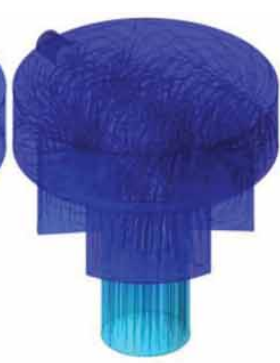

$t=11 \mathrm{~s}$

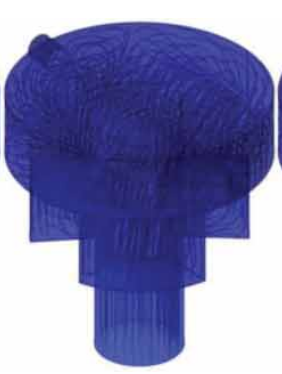

$t=14 \mathrm{~s}$

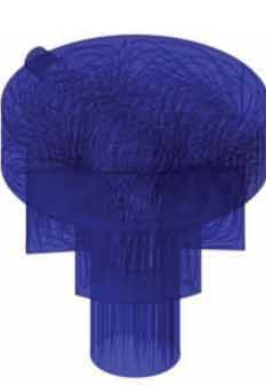

$t=17 \mathrm{~s}$
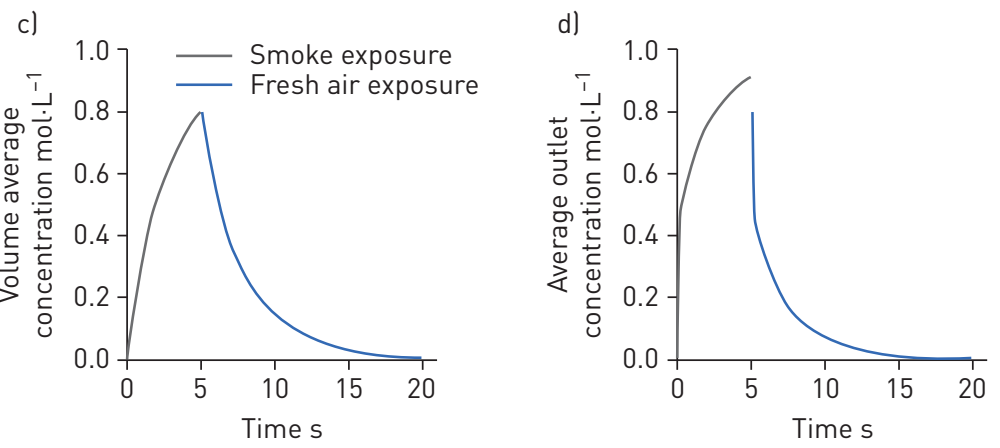

FIGURE 4 Three-dimensional quantitative modelling results of the gas $\left(\mathrm{CO}_{2}\right)$ concentration distribution in an in vitro exposure system chamber: a) real-time $\mathrm{CO}_{2}$ concentration distribution over $5 \mathrm{~s}$ exposure of smoke (initial $\mathrm{CO}_{2}$ concentration modelled at 1.0 mol. $\mathrm{L}^{-1}$ ) showing a gentle gas distribution in the exposure chamber; b) real-time $\mathrm{CO}_{2}$ concentration distribution over $5 \mathrm{~s}$ exposure of fresh air (the initial $\mathrm{CO}$ concentration was the final $\mathrm{CO}_{2}$ concentration in the exposure chamber from the previous smoke exposure and it was assumed that there was no $\mathrm{CO}_{2}$ in the fresh air exposed to the chamber); c) volume average concentration of $\mathrm{CO}_{2}$ in the chamber for one smoke-fresh air cycle would lead to a drop in $\mathrm{CO}_{2}$ concentration in the chamber back to zero; and d) average outlet concentration of $\mathrm{CO}_{2}$ after one smoke-fresh air cycle confirming that exposure kinetics were sufficient to reach a repeatable smoke-air exposure cycle (zero concentration at the outlet).

Therefore, the initial concentration for the fresh air exposure was calculated from the previous step and assumed to be uniform in the entire chamber, as seen in figure $4 \mathrm{~b}$. Figure $4 \mathrm{~b}$ also shows the rate of change and uniformity of the $\mathrm{CO}_{2}$ concentration in the chamber during fresh air exposure. Figure $4 \mathrm{c}$ and $\mathrm{d}$ show the volumetric average $\mathrm{CO}_{2}$ concentration of the chamber and the average $\mathrm{CO}_{2}$ concentration at the outlet of the chamber, respectively. The simulation results confirmed that the $\mathrm{CO}_{2}$ concentration in the chamber reached zero after the first fresh air exposure, suggesting that the cells would experience a similar pattern for each cycle, thereby the size of the smoke exposure chamber was small enough to let a fast and uniform diffusion occur in the chamber. This means that the cells would experience the same gas concentration in each cycle.

\section{Impact of in vitro whole cannabis smoke exposure on airway epithelial cell viability and barrier function}

Following quantitative modelling, we next applied IVES for cannabis smoke exposure experiments with multiple biological readouts of relevance to epithelial cell biology. We measured TEER before and after fresh, whole cannabis smoke exposure on primary HBECs. We compared the change in TEER ( $\Delta$ TEER) before and after exposure between cultures that received room air or smoke. Our results suggest that 
individual donor cultures exposed to cannabis smoke in IVES experienced a decrease in epithelial barrier function as compared to air-exposed controls $(\mathrm{p}<0.05)$ (figure $5 \mathrm{a})$. The decline in epithelial barrier function was not associated with any increase in $\mathrm{LDH}$, a measure of cell membrane integrity and cell viability (figure $5 \mathrm{~b}$ ) suggesting that cell cytotoxicity was minimally impacted by our model.

Following whole smoke exposure, cell cultures exhibited qualitative changes in morphology. Qualitative analyses revealed higher incidences of cell lifting, areas of patchiness and a circular shape of the cells relative to controls. A representative microscopic image reflecting these notable changes is shown in figure 5 .

Impact of in vitro whole cannabis smoke exposure on airway epithelial cell immune responses IL-1 cytokine family members are elevated in the context of tobacco smoke exposure to airway epithelial cells and lung tissue [60-62]. We therefore analysed the differential expression of selected IL-1 cytokine family members, IL-1 $\alpha$, IL-1 $\beta$, IL-18, IL-1Ra, in our model of cannabis exposure using IVES, as we have demonstrated significant overlap between airway epithelial cell responses to these two exposures in a submerged monolayer culture system [35]. Trends for elevations in IL-1 $\alpha(p=0.054)$, IL-1 $(p=0.296)$ and IL-18 ( $p=0.064)$ were observed and a significant elevation of IL-1Ra $(p<0.05)$ in five individual donor samples $(\mathrm{n}=5)$ following cannabis smoke exposure relative to room air. On a donor basis, IL-1 $\alpha$, IL-18 and IL-1Ra were elevated in 5 of 5 samples (100\%), whereas IL-1 $\beta$ was elevated in 4 of 5 samples (80\%) (figure 6).

We have demonstrated that cannabis smoke extract suppresses CXCL10 and CCL5 in Calu-3 epithelial cells under submerged monolayer conditions [35]. We therefore analysed CXCL10 and CCL5 levels following cannabis smoke exposure in IVES with primary human airway epithelial cells. We observed no significant changes in both CXCL10 or CCL5 expression (figure 7). On a donor basis 4 of 5 (80\%) donor
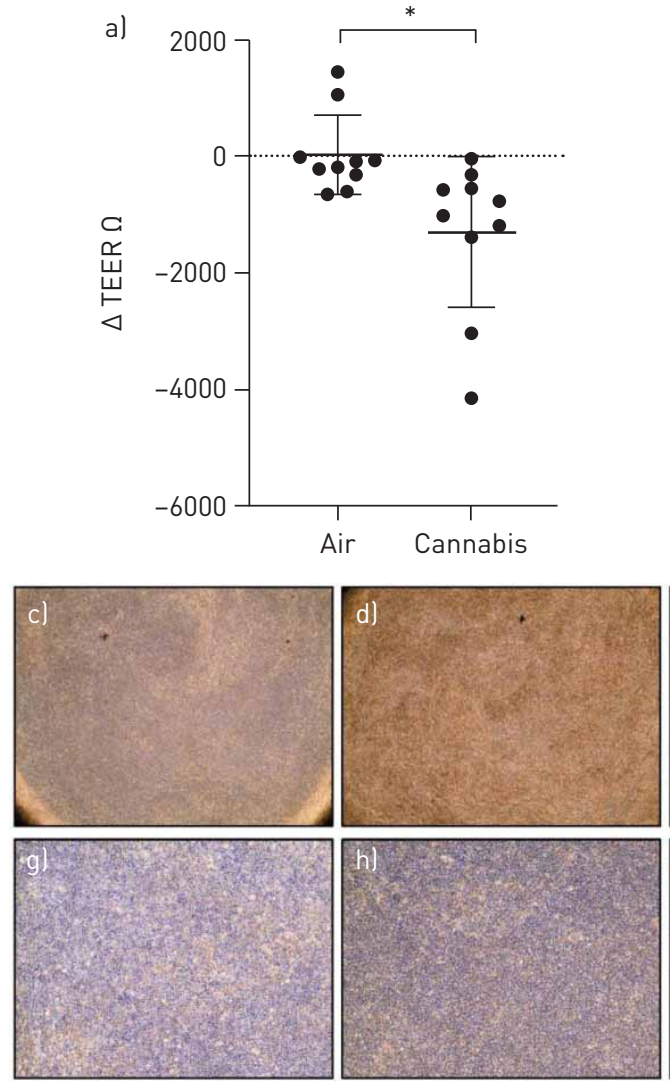

b)

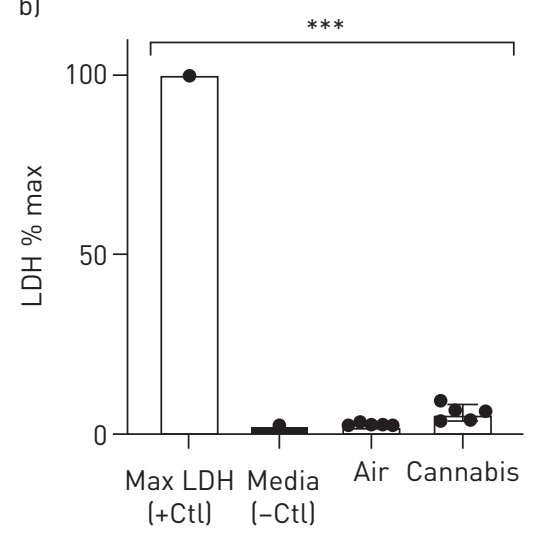

FIGURE 5 a) Change in transepithelial electrical resistance (TEER) from baseline after room air versus whole cannabis smoke exposure. Analysed with paired t-test, $p=0.029, n=10$. b) Lactate dehydrogenase (LDH) expression as a proportion of maximal LDH release, analysed via ANOVA and Tukey's post hoc test. Shows representative microscopy $(\times 40)$ of c) Transwell inserts with human bronchial epithelial cells (HBECs) prior to room air exposure, d) Transwell with HBECs after room air exposure, e) Transwell with HBECs prior to whole cannabis smoke exposure, and f) Transwell with HBECs after whole cannabis smoke exposure (product weight of $0.7 \mathrm{~g})$. Representative microscopy $(\times 100)$ of $\mathrm{g})$ Transwell inserts with HBECs prior to room air exposure, h) Transwell with HBECs after room air exposure, i) Transwell with HBECs prior to whole cannabis smoke exposure, and j) Transwell with HBECs after whole cannabis smoke exposure (product weight of $0.7 \mathrm{gl} .^{*}: \mathrm{p}<0.05 ; * * *: p<0.001$. 
FIGURE 6 Interleukin (IL)-1 cytokine family member quantification in apical washing of primary human airway epithelial cells exposed to air or whole cannabis smoke. a) IL-1 $\alpha$, $\mathrm{p}=0.054$; b) IL-1 $\beta, \mathrm{p}=0.296$; c) IL-18, $\mathrm{p}=0.064$; and d) IL-1R antagonist (IL-1Ra), $\mathrm{p}<0.05$ lanalysed via paired t-tests). *: $p<0.05$.
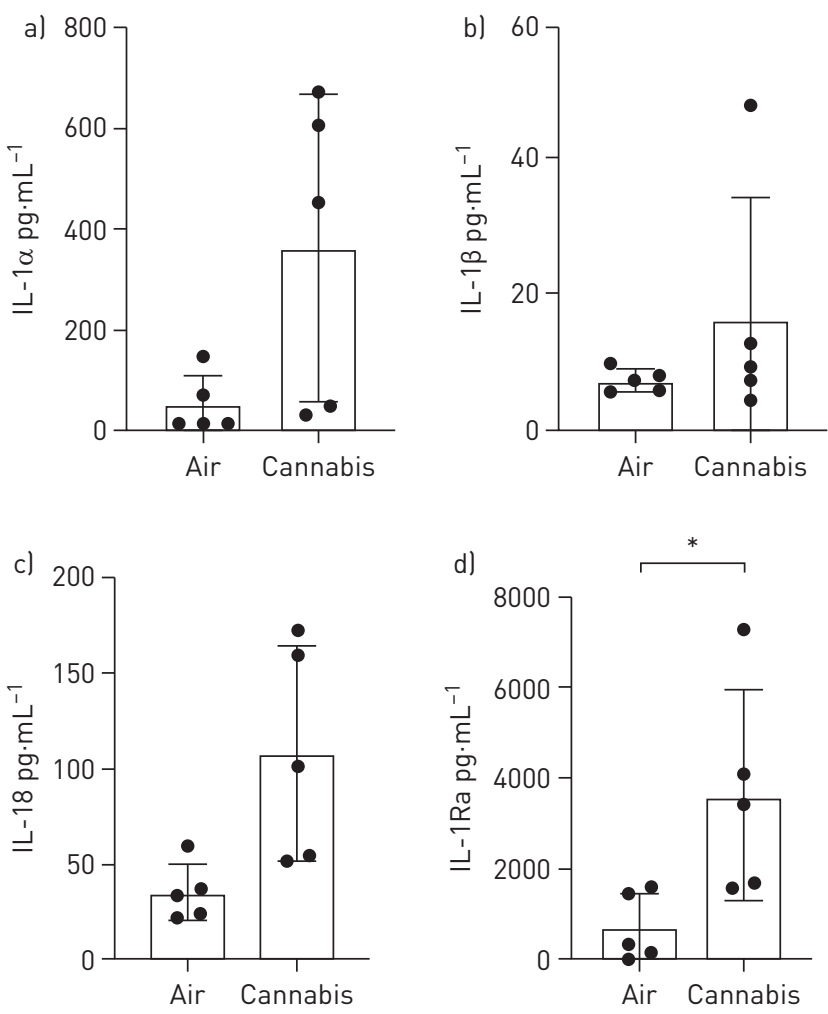

samples displayed suppression of CXCL10 $(\mathrm{p}=0.110)$ and 0 of $5(0 \%)$ donor samples displayed suppression of CCL5 ( $\mathrm{p}=0.252)$.

In vitro whole cannabis smoke exposure induces expression of genes involved in cellular detoxification

We have demonstrated that tobacco and cannabis smoke extract exposures with Calu-3 epithelial cells cultured under submerged monolayer conditions results in elevations in gene expression for CYP1A1 and CYP1B1, both of which function as phase II detoxification enzymes [3]. Additionally, thioredoxin interacting protein (TXNIP) has been shown to inhibit the antioxidative effect of thioredoxin, resulting in an accumulation of reactive oxygen species and cellular stress $[63,64]$. We therefore determined the gene expression level of CYP1A1, CYP1B1 and TXNIP in primary human airway epithelial cells following cannabis smoke exposure with IVES. We demonstrate that cannabis smoke exposure results in robust induction of both gene transcripts in 5 of $5(100 \%)$ donor samples for CYP1A1 $(\mathrm{p}<0.001), 5$ of $5(100 \%)$ donor samples for CYP1B1 $(\mathrm{p}<0.05)$ and suppression of TXNIP in 4 of $5(80 \%)$ donor samples $(\mathrm{p}=0.058)$ (figure 8$)$.

\section{Discussion}

The US Center for Disease Control declares that cigarette smoking is the leading preventable cause of death in the United States [65]. Adding to the pressing concern is the relatively new increase in global

FIGURE 7 Antiviral cytokine quantification in apical washing of primary human airway epithelial cells exposed to air or whole cannabis smoke. a) CXCL10, $p=0.110$; and b) CCL5, $p=0.252(n=5$, analysed via paired t-tests).
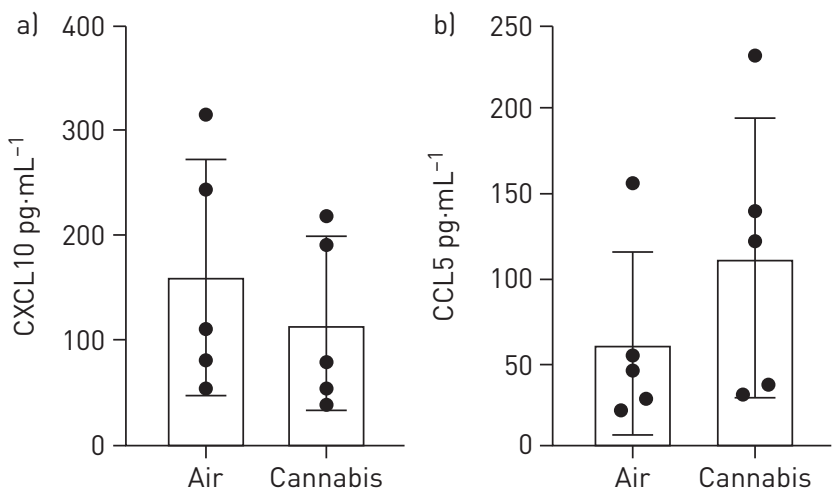

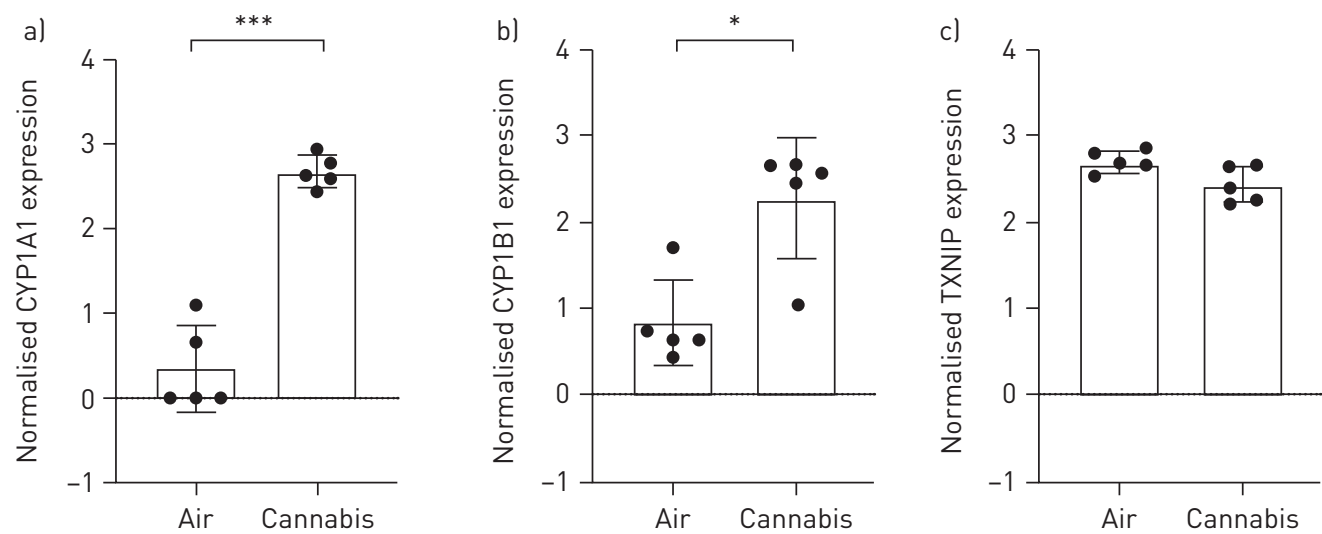

FIGURE 8 Selected oxidative stress genes expressed in primary human airway epithelial cells exposed to air or whole cannabis smoke. a) CYP1A1, $p<0.001$; b) CYP1B1, $p<0.05$; and $c$ ) TXNIP, $p=0.058$ ( $n=5$, analysed via paired t-tests). ${ }^{*}: p<0.05 ;{ }^{* * *}: p<0.001$.

legalisation and practice of smoking cannabis [66-68]. Notably, evidence suggests that cannabis smoke consists of differential components relative to tobacco smoke, which may function as immunomodulatory agents $[26,69,70]$. To determine shared or divergent consequences of cannabis smoke on lung health, relevant experimental data must be generated to inform policy and decision making at the personal and population level. Frequently used low-cost in vitro models of smoke exposure may not adequately reflect the realities of smoke delivery in situ, while advanced smoke exposure model systems, more physiologically relevant, are often expensive and inaccessible for many research groups. To address these constraints and the need for accessible, relevant, in vitro experimental systems, we sought to develop and validate a novel smoke exposure model applicable to various modalities through the conception of IVES.

To capture the benefit of exposing cells directly to smoke while overcoming the shortcomings of the current smoke exposure systems, which are bulky, expensive or lacking in adaptation to custom experimental set-ups [71-75], we utilised 3D-printing technology to design and develop a versatile smoke exposure system that can be easily scaled up or down. Initially, the IVES was designed and fabricated as a single-chamber exposure unit. The purpose of this step was to optimise the size of the chamber considering various criteria such as basal liquid volume, accessibility to Transwell insert and the basal medium, and the fluidic path of smoke exposure. Then, the final design was scaled up to the current IVES as proposed in this work (figures 1 and 2). The fluidic dynamic modelling conducted in this study confirmed that the design of IVES and the exposure protocol were well designed to expose cells in a repeatable fashion. Figure 3 shows a uniform gas flow distribution in IVES with indirect gas exposure to cells, which was critical in creating a stress-free exposure to cells. Additionally, mass transfer results from the simulation revealed that the length of fresh air exposure was sufficient to zero $\mathrm{CO}_{2}$ concentration (figure 4). This in vitro model can be easily redesigned for different applications and purposes. The size of IVES can be changed to fit various sizes of Transwell inserts or more exposure chambers can be integrated with IVES. Moreover, a fluidic path can be added to the basal side of the chambers to create a dynamic flow in the liquid compartment of the system. Overall, the proposed exposure system in this work is inexpensive, easy to use, easy to fabricate and amenable to multiple experimental designs, including smoke, vaping and coexposures with pathogens.

The mucociliary escalator, secreted antimicrobial products and paracellular permeability mediated by intracellular junctions collectively serve to establish the barrier function between the external and internal environments [5]. Human airways rely on the latter, tight and adherens junctions between cells at the apical border, to prevent inhaled pathogens and other insults from causing harm to the airways [5]. In smokers, the epithelium is found to be dysfunctional and abnormally differentiated, leaving a higher risk for viral and bacterial infection [5]. To determine how IVES delivery of cannabis smoke impacted epithelial barrier function, TEER was measured in 10 individual donor primary HBECs prior to and following cannabis smoke exposure. Using IVES as a model for cannabis smoke exposure using primary HBECs, our data suggest that a compromised barrier may be observed in human cannabis smokers. The lungs rely on the formation and strict regulation of a mechanical barrier established by airway epithelial cells [76]. Previous studies have implicated oxidative stress brought on by cigarette smoke with the disruption of epithelial barrier function [77]. Other studies have found that cigarette smoke increases the permeability of human airways disrupting the balance between external fluids and macromolecules through altered regulation of multiple tight junction and adherens junction proteins [78-80]. 
Despite extensive studies of airway epithelial cell barrier function and tobacco smoke exposure, few data are available for cannabis smoke exposure. Using submerged monolayer cultures of Calu-3 cells, we were able to demonstrate that cannabis smoke condition medium was able to reduce barrier function, as assessed by TEER, a response shared with tobacco smoke-conditioned medium [35]. In the present study, we extended our published findings by interrogating how whole cannabis smoke impacted barrier function in primary human airway epithelial cells grown under ALI conditions. Our data confirm that cannabis smoke, similar to tobacco smoke, is able to compromise barrier function. Furthermore, the data establish that monitoring epithelial cell barrier function measurements following exposures using IVES are possible.

Cytokines are signalling molecules crucial to the proper innate and adaptive immune function. They perform a host of essential duties ranging from mitigating viral, bacterial, fungal infections to signalling a cascade of other immunomodulatory agents responding to allergens in the air. Airway inflammation associated with changes in cytokines that regulate immune function is present in both cannabis and tobacco smokers resulting in clinical presentation of coughing, wheezing and the onset of asthma and COPD [21, 27, 81-85]. Notably, the IL-1 family of cytokines has been implicated in acute inflammatory processes as well as linked to cytokine balance disruption in cigarette smokers [25]. IL-1 family cytokine expression at the protein level was assessed in our model, following cannabis smoke exposure in five individual patient donor samples. Our experiments with five independent donors show trends for an increase in IL- $1 \alpha$, IL-1 $\beta$ and IL-18 expression, following cannabis smoke exposure relative to control, findings that are similar to observations made in other studies with tobacco smoke [60-62]. These results indicate an inflammatory response induced by cannabis smoke characterised by IL-1 family cytokines, which may share downstream consequences with tobacco smoke that include neutrophilia driven by an IL-1R-IL-17 axis [86]. We also observed a significant elevation of IL-1Ra following smoke exposure. Notably, other studies have found a suppression of IL-1Ra expression in tobacco smokers, which works by antagonising IL-1 $\alpha$ and IL-1 $\beta$ [87]. In cannabis smoke however, IL-1Ra expression has been shown to be elevated owing to the unclear immunomodulatory features of cannabis active components $[24,88,89]$.

Our published in vitro data using Calu-3 airway epithelial cells under submerged monolayer culture conditions suggest that cannabis smoke extract-conditioned medium attenuates expression of antiviral pathways important in host defence in human airway epithelial cells $[35,36]$. To explore the possibility that whole cannabis smoke exposure of primary human airway epithelial cells grown under ALI-culture conditions behaved similarly, we analysed CXCL10 and CCL5 levels as previously performed $[35,36]$. The current data show negligible changes from the baseline of CXCL10 and CCL5 in primary HBECs. This suggests inherent differences in the model and/or use of primary cells at ALI when compared to cell lines in submerged monolayers. Moreover, cytokines have been shown to not be expressed differentially following cigarette exposure alone; rather, they require viral/viral mimetic challenges prefacing expression [90-92]. It will be relevant for future studies to induce CXCL10/CCL5 through viral/viral mimetic challenges to assess the impact of cannabis smoke on these antiviral cytokines.

Previously, we have shown that aryl hydrocarbon receptor-induced genes associated with oxidative stress, CYP1A1 and CYP1B1, are significantly induced in Calu-3 cells exposed to cannabis and tobacco smoke extracts [35]. Similarly, we have shown that TXNIP was reduced [35]. Other studies have shown similar results of increased oxidative stress, as indicated by dysregulated expression of these same genes in various types of smoke exposure such as tobacco, polycyclic aromatic hydrocarbons, incense smoke and cannabis smoke [93-95]. Consequently, we analysed the expression of CYP1A1, CYP1B1 and TXNIP in primary human epithelial cells exposed to cannabis smoke using IVES. We chose these particular genes because of their robust induction in our Calu-3 cell model with cannabis smoke-conditioned medium. A significant elevation was observed in CYP1A1 and CYP1B1, while a negative trend was observed in TXNIP following smoke exposure, validating IVES for modelling molecular changes in human airway epithelial cells exposed to whole cannabis smoke.

The aim of our study has been to validate and introduce an open-access, disposable, easy-to-use method for whole smoke exposure to airway epithelial cells grown on Transwell inserts. The dosing parameters used in our study served as a means to reliably evoke a cannabis induced effect. To incorporate aspects of human smoke exposure studies we used a modified Foltin puff procedure. In this procedure used for clinical research, human participants are asked to inhale smoke for $5 \mathrm{~s}$, hold for $10 \mathrm{~s}$ and then exhale. We used these durations to define the durations for inhalations, exhalations and periods of rest. To determine the volumes for the inhalations and exhalations, we used the ISO 3308 routine analytical cigarette-smoking machine guideline. To determine the mass of cannabis, we aligned with the Kentucky research-grade cigarette, a standardised product that has $0.7 \mathrm{~g}$ per cigarette. We recognise that these conditions represent a single possible combination that does not provide concentration-response outcomes that may be impacted by length of time for combustion, frequency and volumes of inhalation/exhalation, and mass of cannabis combusted. Despite our single set of conditions, we validate IVES for equal distribution of smoke 
across the four exposure chambers, equal distribution of smoke pressure over the base of the Transwell insert, minimal shear stress across the growth area, a capacity for the human airway epithelial cells to respond to smoke at a cellular and molecular level. Future studies can expand applications for the validated IVES to explore different concentrations, durations of smoke, period of smoke, coexposure with pathogens or introduction of vaping technologies. Additional experiments could be performed to define a no-observed effect level for studies with a toxicology focus.

In this study, we have outlined and validated the developmental parameters and flow simulation and streamlined the exposure protocol to measure epithelial barrier function, cytokine expression and gene expression. We have applied it to an exposure study assessing the impact of cannabis smoke exposure of primary HBECs. IVES shows stark similarities between existing models and promises the ability to generate needed relevant data to inform public health policy and individual user practices.

Conflict of interest: None declared.

Support statement: This work was supported by the McMaster Centre for Medicinal Cannabis Research and the Ontario Lung Association. Funding information for this article has been deposited with the Crossref Funder Registry.

\section{References}

1 Huff R, Carlsten C, Hirota J. An update on immunologic mechanisms in the respiratory mucosa in response to air pollutants. J Allergy Clin Immunol 2019; 143: 1989-2001.

2 Hirota JA, Knight DA. Human airway epithelial cell innate immunity: relevance to asthma. Curr Opin Immunol 2012; 24: 740-746.

3 Iwasaki A, Foxman EF, Molony RD. Early local immune defences in the respiratory tract. Nat Rev Immunol 2017; 17: 7-20.

4 Whitsett JA, Alenghat T. Respiratory epithelial cells orchestrate pulmonary innate immunity. Nat Immunol 2015; 16: $27-35$.

5 Ganesan S, Comstock AT, Sajian US. Barrier function of airway tract epithelium. Tissue Barriers 2013; 1: e24997.

6 Bakshani CR, Morales-Garcia AL, Althaus M, et al. Evolutionary conservation of the antimicrobial function of mucus: A first defence against infection. NPJ Biofilms Microbiomes 2018; 4: 1-12.

7 Kicic A, Sutanto EN, Stevens PT, et al. Intrinsic biochemical and functional differences in bronchial epithelial cells of children with asthma. Am J Respir Crit Care Med 2006; 174: 1110-1118.

8 Steiling $\mathrm{K}$, van den Berge M, Hijazi K, et al. A dynamic bronchial airway gene expression signature of chronic obstructive pulmonary disease and lung function impairment. Am J Respir Crit Care Med 2013; 187: 933-942.

9 Xu Y, Mizuno T, Sridharan A, et al. Single-cell RNA sequencing identifies diverse roles of epithelial cells in idiopathic pulmonary fibrosis. JCI Insight 2016; 1: e90558.

10 Broekema M, ten Hacken NHT, Volbeda F, et al. Airway epithelial changes in smokers but not in ex-smokers with asthma. Am J Respir Crit Care Med 2009; 180: 1170-1178.

11 Tamashiro E, Cohen NA, Palmer JN, et al. Effects of cigarette smoking on the respiratory epithelium and its role in the pathogenesis of chronic rhinosinusitis. Braz J Otorhinolaryngol 2009; 75: 903-907.

12 Thorley AJ, Tetley TD. Pulmonary epithelium, cigarette smoke, and chronic obstructive pulmonary disease. Int $J$ Chron Obstruct Pulmon Dis 2007; 2: 409-428.

13 Walters MS, De BP, Salit J, et al. Smoking accelerates aging of the small airway epithelium. Respir Res 2014; 15: 94.

14 Amatngalim GD, Broekman W, Daniel NM, et al. Cigarette smoke modulates repair and innate immunity following injury to airway epithelial cells. PLoS ONE 2016; 11: e0166255.

15 Cantin AM. Cellular response to cigarette smoke and oxidants: adapting to survive. Proc Am Thorac Soc 2010; 7 368-375.

16 Mathis C, Poussin C, Weisensee D, et al. Human bronchial epithelial cells exposed in vitro to cigarette smoke at the air-liquid interface resemble bronchial epithelium from human smokers. Am J Physiol Lung Cell Mol Physiol 2013; 304: L489-L503.

17 Schamberger AC, Staab-Weijnitz CA, Mise-Racek N, et al. Cigarette smoke alters primary human bronchial epithelial cell differentiation at the air-liquid interface. Sci Rep 2015; 5: 8163.

18 Thun MJ, Henley SJ, Calle EE. Tobacco use and cancer: an epidemiologic perspective for geneticists. Oncogene 2002; 21: 7307-7325.

19 United Nations. World Drug Report. New York, United Nations, 2019.

20 Government of Canada. Canadian Cannabis Survey 2018 Summary. www.canada.ca/en/services/health/ publications/drugs-health-products/canadian-cannabis-survey-2018-summary.html Date last updated: November 19, 2018. Date last accessed: September 15, 2020. Date last updated: November 19, 2018.

21 Moir D, Rickert WS, Levasseur G, et al. A comparison of mainstream and sidestream marijuana and tobacco cigarette smoke produced under two machine smoking conditions. Chem Res Toxicol 2008; 21: 494-502.

22 Tashkin DP, Coulson AH, Clark VA, et al. Respiratory symptoms and lung function in habitual heavy smokers of marijuana alone, smokers of marijuana and tobacco, smokers of tobacco alone, and nonsmokers. Am Rev Respir Dis 1987; 135: 209-216.

23 Wu TC, Tashkin DP, Djahed B, et al. Pulmonary hazards of smoking marijuana as compared with tobacco. N Engl J Med 1988; 318: 347-351.

24 Melamede R. Harm reduction-the cannabis paradox. Harm Reduct J 2005a; 2: 17

25 Nyunoya T, Mebratu Y, Contreras A, et al. Molecular processes that drive cigarette smoke-induced epithelial cell fate of the lung. Am J Respir Cell Mol Biol 2014; 50: 471-482.

26 Kaplan BLF, Springs AEB, Kaminski NE. The profile of immune modulation by cannabidiol (CBD) involves deregulation of nuclear factor of activated T cells (NFAT). Biochem Pharmacol 2008; 76: 726-737. 
27 Nagarkatti P, Pandey R, Rieder SA, et al. Cannabinoids as novel anti-inflammatory drugs. Future Med Chem 2009; 1: 1333-1349.

28 Tashkin DP, Shapiro BJ, Lee YE, et al. Effects of smoked marijuana in experimentally induced asthma. Am Rev Respir Dis 1975; 112: 377-386.

29 Vachon L, FitzGerald MX, Solliday NH, et al. Single-dose effects of marihuana smoke. Bronchial dynamics and respiratory-center sensitivity in normal subjects. N Engl J Med 1973; 288: 985-989.

30 St-Laurent J, Proulx L-I, Boulet L-P, et al. Comparison of two in vitro models of cigarette smoke exposure. Inhal Toxicol 2009; 21: 1148-1153.

31 Wan J, Johnson M, Schilz J, et al. Evaluation of in vitro assays for assessing the toxicity of cigarette smoke and smokeless tobacco. Cancer Epidemiol Biomarkers Prev 2009; 18: 3263-3304.

32 Ji M, Zhang Y, Li N, et al. Nicotine component of cigarette smoke extract (CSE) decreases the cytotoxicity of CSE in BEAS-2B cells stably expressing human cytochrome P450 2A13. Int J Environ Res Public Health 2017; 14: 1221.

33 Jamieson KC, Traves SL, Kooi C, et al. Rhinovirus and bacteria synergistically induce IL-17C release from human airway epithelial cells to promote neutrophil recruitment. J Immunol 2019; 202: 160-170.

34 Gellner C, Reynaga DD, Leslie FM. Cigarette smoke extract: a preclinical model of tobacco dependence. Curr Protoc Neurosci 2016; 77: 9.54.1-9.54.10.

35 Aguiar JA, Huff RD, Tse W, et al. Transcriptomic and barrier responses of human airway epithelial cells exposed to cannabis smoke. Physiol Rep 2019; 7: e14249.

36 Huff RD, Aguiar JA, Tse W, et al. Effect of long-acting $\beta$-agonists/glucocorticoids on human airway epithelial cell cytokine, transcriptomic and oxidative stress responses to cannabis smoke. ERJ Open Res 2020; 6: 00265-2019.

37 Lange P. Cannabis and the lung. Thorax 2007; 62: 1036-1037.

38 Schwartz R. Legalize marijuana without the smoke. CMAJ 2017; 189: E137-E138.

39 Tashkin DP, Gliederer F, Rose J, et al. Tar, CO and delta 9THC delivery from the 1st and 2nd halves of a marijuana cigarette. Pharmacol Biochem Behav 1991; 40: 657-661.

40 Azzopardi D, Haswell LE, Foss-Smith G, et al. Evaluation of an air-liquid interface cell culture model for studies on the inflammatory and cytotoxic responses to tobacco smoke aerosols. Toxicol In Vitro 2015; 29: 1720-1728.

41 Jiang D, Schaefer N, Chu HW. Air-liquid interface culture of human and mouse airway epithelial cells. Methods Mol Biol 2018; 1809: 91-109.

42 Aufderheide M, Mohr U. CULTEX - a new system and technique for the cultivation and exposure of cells at the air/liquid interface. Exp Toxicol Pathol 1999; 51: 489-490.

43 Deschl U, Vogel J, Aufderheide M. Development of an in vitro exposure model for investigating the biological effects of therapeutic aerosols on human cells from the respiratory tract. Exp Toxicol Pathol 2011; 63: 593-598.

44 Ritter D, Knebel JW, Aufderheide M. In vitro exposure of isolated cells to native gaseous compounds Development and validation of an optimized system for human lung cells. Exp Toxicol Pathol 2001; 53: 373-386.

45 Thorne D, Adamson J. A review of in vitro cigarette smoke exposure systems. Exp Toxicol Pathol 2013; 65: $1183-1193$.

46 Adamson J, Azzopardi D, Errington G, et al. Assessment of an in vitro whole cigarette smoke exposure system: the Borgwaldt RM20S 8-syringe smoking machine. Chem Cent J 2011; 5: 50.

47 Aufderheide M, Knebel JW, Ritter D. An improved in vitro model for testing the pulmonary toxicity of complex mixtures such as cigarette smoke. Exp Toxicol Pathol 2003; 55: 51-57.

48 Bom Bick DW, Ayres PH, Doolittle DJ. Cytotoxicity assessment of whole smoke and vapor phase of mainstream and sidestream cigarette smoke from three Kentucky reference cigarettes. Toxicol Methods 1997; 7: 177-190.

49 Scian MJ, Oldham MJ, Kane DB, et al. Characterization of a whole smoke in vitro exposure system (Burghart Mimic Smoker-01). Inhal Toxicol 2009; 21: 234-243.

50 Abdallah SJ, Smith BM, Ware MA, et al. Effect of vaporized cannabis on exertional breathlessness and exercise endurance in advanced chronic obstructive pulmonary disease. A randomized controlled trial. Ann Am Thorac Soc 2018; 15: 1146-1158.

51 Chait LD, Corwin RL, Johanson CE. A cumulative dosing procedure for administering marijuana smoke to humans. Pharmacol Biochem Behav 1988; 29: 553-557.

52 Foltin RW, Fischman MW, Pedroso JJ, et al. Marijuana and cocaine interactions in humans: cardiovascular consequences. Pharmacol Biochem Behav 1987; 28: 459-464.

53 Ramesh D, Haney M, Cooper ZD. Marijuana's dose-dependent effects in daily marijuana smokers. Exp Clin Psychopharmacol 2013; 21: 287-293.

54 Wilsey B, Marcotte TD, Deutsch R, et al. Low-dose vaporized cannabis significantly improves neuropathic pain. J Pain 2013; 14: 136-148.

55 Wilsey B, Marcotte TD, Deutsch R, et al. An exploratory human laboratory experiment evaluating vaporized cannabis in the treatment of neuropathic pain from spinal cord injury and disease. J Pain 2016; 17: 982-1000.

56 Dai $\mathrm{M}$, Wang $\mathrm{P}$, Boyd $\mathrm{AD}$, et al. Evolving gene/transcript definitions significantly alter the interpretation of GeneChip data. Nucleic Acids Res 2005; 33: e175.

57 Piccolo SR, Sun Y, Campbell JD, et al. A single-sample microarray normalization method to facilitate personalized-medicine workflows. Genomics 2012; 100: 337-344.

58 Huber W, Carey VJ, Gentleman R, et al. Orchestrating high-throughput genomic analysis with bioconductor. Nat Methods 2015; 12: 115-121.

59 Wilke CR, Lee CY. Estimation of diffusion coefficients for gases and vapors. Ind Eng Chem 1955; 47: 1253-1257.

60 Churg A, Zhou S, Wang X, et al. The role of interleukin-1beta in murine cigarette smoke-induced emphysema and small airway remodeling. Am J Respir Cell Mol Biol 2009; 40: 482-490.

61 Kang M-J, Homer RJ, Gallo A, et al. IL-18 is induced and IL-18 receptor alpha plays a critical role in the pathogenesis of cigarette smoke-induced pulmonary emphysema and inflammation. J Immunol 2007; 178: 1948-1959.

62 Pauwels NS, Bracke KR, Dupont LL, et al. Role of IL- $1 \alpha$ and the Nlrp3/caspase-1/IL-1 $\beta$ axis in cigarette smoke-induced pulmonary inflammation and COPD. Eur Respir J 2011; 38: 1019-1028.

63 Cho JM, Yoon S-J, Kim W, et al. Oxidative stress-mediated TXNIP loss causes RPE dysfunction. Exp Mol Med 2019; 51: 1-13. 
64 Junn E, Han SH, Im JY, et al. Vitamin D3 up-regulated protein 1 mediates oxidative stress via suppressing the thioredoxin function. J Immunol 2000; 164: 6287-6295.

65 CDC TobaccoFree. Health Effects of Cigarette Smoking. Centers for Disease Control and Prevention, 2019.

66 Cerdá M, Wall M, Feng T, et al. Association of state recreational marijuana laws with adolescent marijuana use. JAMA Pediatr 2017; 171: 142-149.

67 Leyton M. Cannabis legalization: did we make a mistake? Update 2019. J Psych Neurosci 2019; 44: 291-293.

68 Volkow ND, Baler RD, Compton WM, et al. Adverse health effects of marijuana use. N Engl J Med 2014; 370 : 2219-2227.

69 Ashton JC, Hancox RJ. the case for cannabinoid CB1 receptors as a target for bronchodilator therapy for $\beta$-agonist-resistant asthma. Curr Drug Targets 2018; 19: 1344-1349.

70 Klein TW. Cannabinoid-based drugs as anti-inflammatory therapeutics. Nat Rev Immunol 2005; 5: 400-411.

71 Amatngalim GD, van Wijck Y, de Mooij-Eijk Y, et al. Basal cells contribute to innate immunity of the airway epithelium through production of the antimicrobial protein RNase 7. J Immunol 2015; 194: 3340-3350.

72 de Bruijne K, Ebersviller S, Sexton KG, et al. Design and testing of electrostatic aerosol in vitro exposure system (EAVES): an alternative exposure system for particles. Inhal Toxicol 2009; 21: 91-101.

73 Herr C, Beisswenger C, Hess C, et al. Suppression of pulmonary innate host defence in smokers. Thorax 2009; 64 $144-149$.

74 Lenz AG, Karg E, Lentner B, et al. A dose-controlled system for air-liquid interface cell exposure and application to zinc oxide nanoparticles. Part Fibre Toxicol 2009; 6: 32.

75 Raredon MSB, Ghaedi M, Calle EA, et al. A rotating bioreactor for scalable culture and differentiation of respiratory epithelium. Cell Med 2015; 7: 109-121.

76 Heijink IH, Brandenburg SM, Postma DS, et al. Cigarette smoke impairs airway epithelial barrier function and cell-cell contact recovery. Eur Respir J 2012; 39: 419-428.

77 Boardman KC, Aryal AM, Miller WM, et al. Actin re-distribution in response to hydrogen peroxide in airway epithelial cells. J Cell Physiol 2004; 199: 57-66.

78 Mishra R, Foster D, Vasu VT, et al. cigarette smoke induces human epidermal receptor 2-dependent changes in epithelial permeability. Am J Respir Cell Mol Biol 2016; 54: 853-864.

79 Olivera DS, Boggs SE, Beenhouwer C, et al. Cellular mechanisms of mainstream cigarette smoke-induced lung epithelial tight junction permeability changes in vitro. Inhal Toxicol 2007; 19: 13-22.

80 Tatsuta M, Kan-O K, Ishii Y, et al. Effects of cigarette smoke on barrier function and tight junction proteins in the bronchial epithelium: protective role of cathelicidin LL-37. Respir Res 2019; 20: 251.

81 Aldington S, Williams M, Nowitz M, et al. Effects of cannabis on pulmonary structure, function and symptoms. Thorax 2007; 62: 1058-1063.

82 Costenbader KH, Karlson EW. Cigarette smoking and autoimmune disease: what can we learn from epidemiology? Lupus 2006; 15: 737-745.

83 Hancox RJ, Shin HH, Gray AR, et al. Effects of quitting cannabis on respiratory symptoms. Eur Respir J 2015; 46 : $80-87$.

84 Joshi M, Joshi A, Bartter T. Marijuana and lung diseases. Curr Opin Pulm Med 2014; 20: 173-179.

85 Lee J, Taneja V, Vassallo R. Cigarette smoking and inflammation: cellular and molecular mechanisms. J Dent Res 2012; 91: 142-149.

86 Roos AB, Sethi S, Nikota J, et al. IL-17A and the promotion of neutrophilia in acute exacerbation of chronic obstructive pulmonary disease. Am J Respir Crit Care Med 2015; 192: 428-437.

87 Shiels MS, Katki HA, Freedman ND, et al. Cigarette smoking and variations in systemic immune and inflammation markers. I Natl Cancer Inst 2014; 106: dju294.

88 Melamede R. Cannabis and tobacco smoke are not equally carcinogenic. Harm Reduct J 2005b; 2: 21.

89 Molina-Holgado F, Pinteaux E, Moore JD, et al. Endogenous interleukin-1 receptor antagonist mediates anti-inflammatory and neuroprotective actions of cannabinoids in neurons and glia. J Neurosci 2003; 23: 6470-6474.

90 Eddleston J, Lee RU, Doerner AM, et al. Cigarette smoke decreases innate responses of epithelial cells to rhinovirus infection. Am J Respir Cell Mol Biol 2011; 44: 118-126.

91 Hudy MH, Traves SL, Wiehler S, et al. Cigarette smoke modulates rhinovirus-induced airway epithelial cell chemokine production. Eur Respir J 2010; 35: 1256-1263.

92 Hudy MH, Traves SL, Proud D. Transcriptional and epigenetic modulation of human rhinovirus-induced CXCL10 production by cigarette smoke. Am J Respir Cell Mol Biol 2013; 50: 571-582.

93 Al-Arifi MN, Maayah ZH, Alshamrani AA, et al. Impact of cigarette smoke exposure on the expression of cardiac hypertrophic genes, cytochrome P450 enzymes, and oxidative stress markers in rats. J Toxicol Sci 2012; 37: 1083-1090.

94 Hussain T, Al-Attas OS, Al-Daghri NM, et al. Induction of CYP1A1, CYP1A2, CYP1B1, increased oxidative stress and inflammation in the lung and liver tissues of rats exposed to incense smoke. Mol Cell Biochem 2014; 391: $127-136$

95 Roth MD, Marques-Magallanes JA, Yuan M, et al. Induction and regulation of the carcinogen-metabolizing enzyme CYP1A1 by marijuana smoke and 89 -tetrahydrocannabinol. Am J Respir Cell Mol Biol 2001; 24: 339-344. 